\title{
BEHAVIOURAL RESPONSES OF CANE TOAD (RHINELLA MARINA) ADULTS AND TADPOLES TO CHEMICAL CUES
}

\author{
Takashi Haramura* \\ The Hakubi Center for Advanced Research, Kyoto University, \\ Yoshida-honmachi, Sakyo-ku, Kyoto 606-8302, Japan
}

\begin{abstract}
Pheromonal communication may be possible to control the invader animal. Pheromone-induced behavioural changes could be exploited to control invasive species such as the cane toad (Rhinella marina). Injured cane toad tadpoles are known to produce species-specific chemical cues that alert conspecific tadpoles to danger. These chemical cues reduce both the survival rate of other tadpoles and body size at metamorphosis, and suggest that cane toad tadpoles express chemical substances that control the behaviour of other tadpoles. Identification of the chemical substance(s) involving in tadpole could lead to the development of methods to control the behaviour of cane toad. Here, the behaviour of cane toad adults and tadpoles was characterized following exposure to chemical substances extracted from dead cane toad tadpoles using methanol $(\mathrm{MeOH})$ or distilled water $\left(\mathrm{H}_{2} \mathrm{O}\right)$. Adult toads showed signs of avoiding water to which the $\mathrm{H}_{2} \mathrm{O}$-extracted chemical cue had been added. By contrast, no differences were observed in the swimming behaviour of tadpoles (control, $\mathrm{MeOH}$ or $\mathrm{H}_{2} \mathrm{O}$-extracted samples). These data indicate that development of a chemicalbased behaviour control method will require more detailed chemical analyses. We used dead tadpoles to extract chemical substrate, but in future studies, the potential behaviour-controlling chemical cues should be extracted from live cane toad tadpoles.
\end{abstract}

Key words: Invasive animals, cane toad, chemical cues, behavioural response, controlling methods

\section{INTRODUCTION}

Animals utilize a wide variety of sensory signals to communicate with each other, and the nature of these signals and the responses they elicit may be important characteristics of a species (Leavesley and Magrath 2005). One of the most common means of communication involves conveying information to conspecifics about the approach of a predator. Chemical signals can also provide early warning of the presence or approach of a predator. For example, the larvae of many anuran species have well-developed pheromonal communication systems (Summey and Mathis 1998, Spieler and Linsenmair 1999, Rajchard 2006). When disturbed or injured, a phylogenetically diverse array of larval anurans produce alarm pheromones that induce behavioural responses to conspecifics (Hagman and Shine 2008, 2009a).

*Author for correspondence: <haramura.takashi.2n@kyoto-u.ac.jp>.

(c) 2017 Zoological Society of Bangladesh DOI: http://dx.doi.org/10.3329/bjz.v45i2.35710 
A potential approach for controlling invasive anuran species is to exploit their pheromonal communication systems. Cane toads (Rhinella marina) are large, highly toxic anurans native to Central and South America, but they have been introduced to many countries worldwide as a means of controlling agricultural insect pests, such as in the case of sugarcane production. However, cane toads have caused significant ecological disruption to native ecosystems in the areas to which they have been introduced (Lever 2001). In particular, their potent toxins have caused dramatic reductions in native animal populations (Lever 2001, Phillips et al. 2003). Cane toads were also introduced on Ishigaki Island of Okinawa Prefecture, Japan, and this species is now the only representative of its genus on the island. This situation provides an excellent opportunity for testing control measures targeting lineage-specific features of the cane toad communication system (Wassersug 1997).

Studies of chemical cues produced by cane toads have been conducted in Australia, where cane toads were also introduced. Most research on anuran alarm pheromones have documented avoidance of crushed-conspecific cues by post-metamorphic anurans and tadpoles (Chivers et al. 1999, Hagman and Shine 2008). From this result, toad metamorphos are restricted to specific microhabitats (Freeland and Martin 1985, Alford et al. 1995). Thus, cane toad populations could be controlled by exploiting their chemical communication system.

Can we isolate chemical substances that affect the behaviour of adults or tadpoles? From Australian research, the alarm pheromone that cane toads dislike is from live toad-tadpoles crashed. It may be suggesting that the chemical substance of alarm pheromone is in own tadpole body. Isolation of this chemical substance (controlling toad behaviour) could facilitate the development of a powerful method for controlling cane toad populations. In the present study, therefore, the behavioural responses of cane toad adults and tadpoles to chemical substances extracted were investigated as the first step toward developing such a control method using chemical cues.

\section{MATERIAL AND METHODS}

Cane toads are among the largest anurans, with a maximum body mass sometimes exceeding $1 \mathrm{~kg}$ (Tyler 1975, Pramuk 2006). However, adults generally average around $500 \mathrm{~g}$, with females growing larger than males (Lever 2001). In 1932, 150 cane toads were translocated from Puerto Rico to Hawaii (Lever 2001). In 1935, descendants of these toads were taken from Hawaii to Taiwan, and over the next 4 years that Taiwanese population was the source of further translocations to the Daito Islands of Japan (Lever 2001). In 1978, 
approximately 10 - 15 toads were moved from the Daito Islands to Ishigaki Island, in southern Japan (Ota 1999). Ishigaki is one of the southernmost islands within an archipelago that stretches southwest from Okinawa $\left(24^{\circ} 36^{\prime} 52^{\prime \prime} \mathrm{N}, 124^{\circ} 15^{\circ} 62^{\prime \prime} \mathrm{E}\right)$. The climate of Ishigaki is subtropical, and cane toads breed there in a wide variety of waterbodies, including paddy fields, ponds, and artificial pools in sugarcane fields. Cane toads have caused the death of native snakes, which are fatally poisoned when they attempt to consume the toads (Kidera and Ota 2008). Although data from Japan are limited, the same mechanism of impact has devastated populations of some large predator species in Australia (Shine 2010).

Collection of animals: A total of 49 adult cane toads were collected by hand. Toads were collected from sugarcane fields and held in 45-L buckets until used. All individuals were captured and used in experiments within the same night. Tadpoles $(n=18)$ were collected from paddy fields, which are used as breeding areas by cane toads. These tadpoles were also held in 45-L buckets and used within two days of collection.

Sample extraction: Frozen cane toad tadpoles transported to Kyoto University from Ishigaki were crushed finely under liquid nitrogen, and divided into two samples. One sample was added $1 \mathrm{ml}$ distilled water $\left(\mathrm{H}_{2} \mathrm{O}\right)$, and another sample was added $1 \mathrm{ml}$ methanol (MeOH; Wako Pure Chemical Industries, Ltd.). In below, I showed that chemical substance with distilled $\mathrm{H}_{2} \mathrm{O}$ was " $\mathrm{H}_{2} \mathrm{O}$ ", and with methanol was " $\mathrm{MeOH}$ ". Each sample contained 0.21-0.22 g of crashed tadpoles. Each sample was extracted by ultrasonic waves (room temperature) for $1 \mathrm{~min}$, and again in the laboratory for $2 \mathrm{~min}$. After that, the samples were centrifuged $(13,000 \mathrm{rpm}, 5 \mathrm{~min})$, and the supernatant fluid was collected. The sample extracted by $\mathrm{MeOH}$ was evaporated by using evaporator, and was dissolved with distilled water as an equal volume. This series of steps gave the liquid chemical substrate with $0.8 \mathrm{ml}$ in each extracted method (both $\mathrm{H}_{2} \mathrm{O}$ and $\mathrm{MeOH}$ ), and chemical substance by each extracted method was difference. These liquid chemical substances were frozen, and transported to Ishigaki. The frozen chemical substances were thawed prior to use in experiments, and I used in this experiment.

Experiments with adult cane toads: The mean body size of collected toads averaged $121.85 \mathrm{~g}$ (102.14 mm snout-urostyle length [SUL]) for males and $115.50 \mathrm{~g}$ ( $96.28 \mathrm{~mm}$ SUL) for females in this study. Female cane toads are generally bigger that males (Lever 2001), and, in this sutdy, I prepared the similar body size toads. Two plastic containers $(53 \times 32 \times 6 \mathrm{~cm})$ were prepared that allowed the adult cane toads to move between the containers on a gentle slope. The containers were surrounded by a wire wall (height: $55 \mathrm{~cm}$ ) to prevent 
the toads from escaping. One container was filled with tap water $(12 \mathrm{~L})$, and the other was filled with tap water $(12 \mathrm{~L})$ containing $0.2 \mathrm{ml}$ of either the $\mathrm{MeOH}$ - or $\mathrm{H}_{2} \mathrm{O}$-extracted chemical substance. For the control trial, both containers were filled with tap water only. Initially, one adult cane toad was placed in the center of the arena (on the center of the gentle slope). After 5, 10, 15, and 20 minutes checked the container repeated was checked. After that, a new toad, and same experiment was conducted again. Because only a small amount of chemical substance could be extracted (this was a pilot study, and sample extraction was costly), a total of three trials (three individuals) were conducted repeatedly in one night. The experiments were carried out between 2200 and 2500 hrs.

Experiments with cane toad tadpoles: All tadpoles were stage 21 - 23 (Gosner 1960) and ranged from 11.05-14.69 $\mathrm{mm}$ in size. A digital camera (Panasonic HC-V720M) was mounted at a height of about $1.5 \mathrm{~m}$ above the experimental cup. Experimental cup was filled with tap water $(300 \mathrm{ml})$. For each trial, one tadpole was placed in each cup, and single chemical cue sample was then introduced. Each treatment had six replicate trials (six tadpoles were used in each treatment). Recording period of swimming performance of tadpole was setting 20 min because of referencing the previous studies of tadpole behaviour (Mogali et al. 2013, Polo-Cavia et al. 2016). The digital camera recording duration was $20 \mathrm{~min}$. After each trial, all cups were rinsed and dried thoroughly, and the water was changed. To ensure statistical independence between replicates, each tadpole was used only once, against a single chemical cue or control treatment. When the experiment was started, $0.1 \mathrm{ml}$ of either the $\mathrm{MeOH}-$ or $\mathrm{H}_{2} \mathrm{O}$-extracted chemical cue sample was added to each cup. For the control, $0.1 \mathrm{ml}$ of tap water was added. The experiments were carried out between 1200 $\mathrm{h}$ and $1600 \mathrm{hrs}$.

Two behavioural variables were assessed from the digital recordings. The experiments were divided into four 5-min periods $(5,10,15$, and $20 \mathrm{~min})$. During each 5-min period, two measures of swimming performance were evaluated: the number of tadpoles swimming, and the time of one swimming behaviour of tadpole.

Statistical analysis: All analyses were carried out using JMP software (ver. 11; SAS Institute, Cary, NC, USA). To determine whether adult cane toads avoided water containing the chemical cue, the data for each time period $(5,10$, 15 and $20 \mathrm{~min}$ ) were evaluated using the $\square 2$ test. In tadpole experiment, the number of tadpoles swimming evaluated using the Kruskal-Wallis test, with treatment (control, $\mathrm{MeOH}$ or $\mathrm{H}_{2} \mathrm{O}$ extraction), and the time of one swimming behaviour during each 5-min period were evaluated using the Generalized Linear Model (GLM), with treatment (control, $\mathrm{MeOH}$ or $\mathrm{H}_{2} \mathrm{O}$ extraction) and the 
time $(5,10,15$, or $20 \mathrm{~min})$ as explanatory variables. The level of statistical significance was set at $\mathrm{p}=0.05$.

\section{RESULTS AND DISCUSSION}

Experiments with adult cane toads: The overall ranges of water temperature and $\mathrm{pH}$ were $18.9-32.3^{\circ} \mathrm{C}$ and $8.7-10.7$, respectively. There was no significant difference in either mean water temperature or $\mathrm{pH}$ between water with and without the chemical cue sample (water temperature: $\mathrm{t}$-test, $\mathrm{t}=-0.748, \mathrm{p}>$ 0.05; $\mathrm{pH}: \mathrm{t}=0.060, \mathrm{p}>0.05$ ).

Because the number of female cane toads was small, the data included results for both males and females. A total of 49 adults (male: 33, female: 16) were used in this experiments, and the number of males and females was 13 (male: 7, female: 6) for the control, 20 (male: 12, female: 8) for the $\mathrm{MeOH}-$ extracted chemical cue, and 16 (male: 14, female: 2) for the $\mathrm{H}_{2} \mathrm{O}$-extracted chemical cue. In the case of using $\mathrm{H}_{2} \mathrm{O}$-extracted chemical cue, the number of toads avoiding water containing the chemical cue increased slightly (but not significantly) over time $\left(\chi^{2}=6.931, \mathrm{p}=0.074\right.$; Fig. 1). In the other two trials (Control and $\mathrm{MeOH}$-extracted chemical cue), no significant differences were observed (Control: $\chi^{2}=0.000, \mathrm{p}=1.000 ; \mathrm{MeOH}: \chi^{2}=1.587, \mathrm{p}=0.662$; Fig. 1).

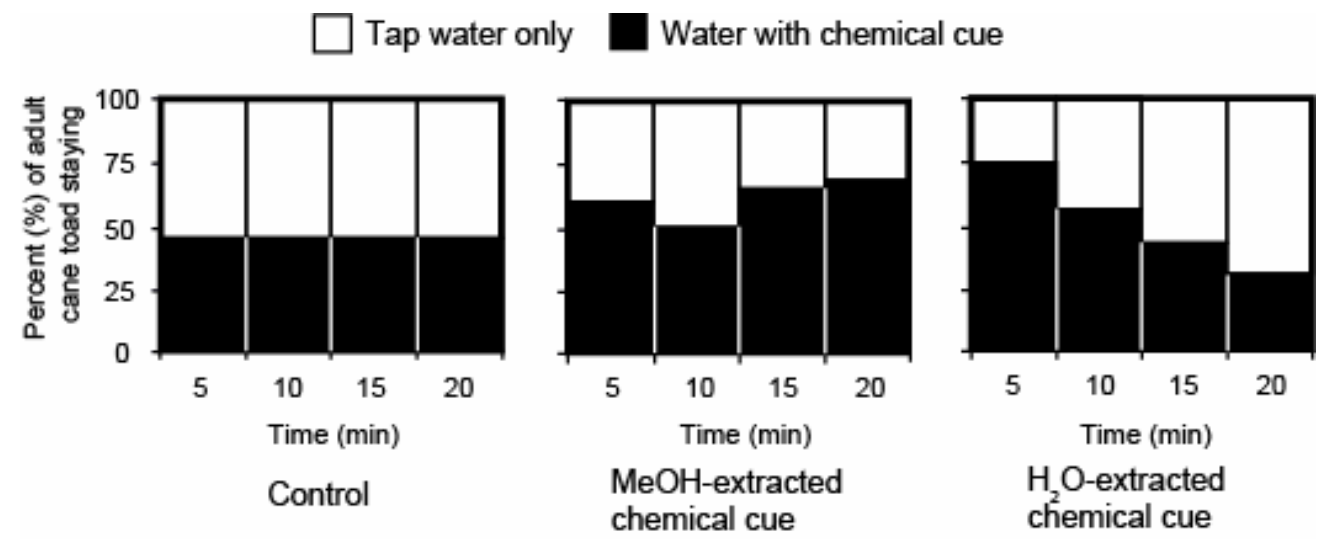

Fig. 1. Per cent which container adult cane toad was staying after 5, 10, 15, and 20 min.

Experiments with cane toad tadpoles: The overall ranges of water temperature and $\mathrm{pH}$ were $22.7-23.0 \mathrm{C}$ and $10.0-10.3$, respectively. No significant differences in the number of tadpoles swimming during each 5-min period were observed (Kruskal-Wallis test, $\chi^{2}=0.723$, $\mathrm{df}=2, \mathrm{p}>0.05$ ).

The time of one swimming behaviour during each 5-min period was 
increased with time (tadpoles were swimming for long time in one swimming), however, there was no significant difference in both between treatments and these interaction (time effect: $\mathrm{df}=3, \mathrm{~F}=44.33, \mathrm{p}<0.001$; treatment: $\mathrm{df}=2, \mathrm{~F}=$ 0.79, $\mathrm{p}>0.05$; time $\times$ treatment: $\mathrm{df}=6, \mathrm{~F}=0.95, \mathrm{p}>0.05$; Fig. 2).

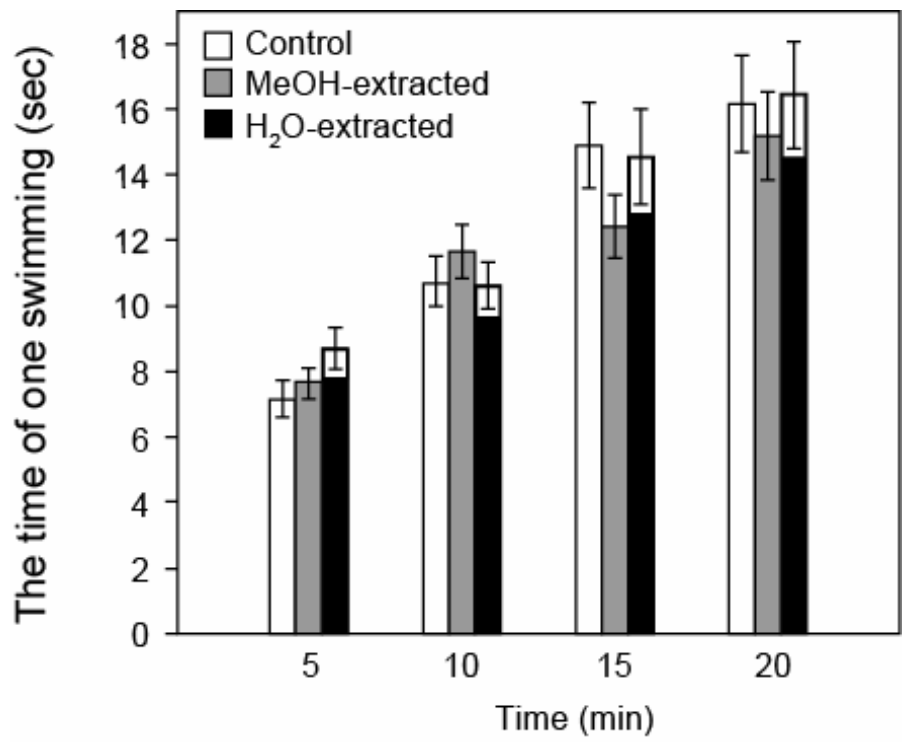

Fig. 2. The time of one swimming behaviour of tadpoles in each 5-min period. Bar is mean $\pm \mathrm{SE}$.

Adult cane toads exhibited a slight reaction to the chemical cue extracted with $\mathrm{H}_{2} \mathrm{O}$. However, tadpoles of cane toad did not react to chemical cue samples extracted using either $\mathrm{H}_{2} \mathrm{O}$ or $\mathrm{MeOH}$. These results indicate that development of a chemical-based behaviour control method for cane toads will require more detailed chemical research.

The results of this study could have been caused by the use of dead rather than living tadpoles for extraction of the chemical substrate. Dead cane toad tadpoles was used because Japanese law prohibits the transport of live cane toads from Ishigaki Island (transport is allowed with prior permission). There is also possibility that dead tadpoles do not contain chemical substrate such as alarm pheromones. The results of this study could represent the first step in the development of a control method using chemical cues, as living tadpoles may be capable of expressing chemical substances such as alarm cues. It could therefore be useful to future development of a chemical control method for cane toads. 
The sensitivity of post-metamorphic cane toads to chemical cues from crushed living tadpoles is high, which offers promise for the development of innovative control methods of cane toad (Hagman and Shine 2008). Hagman and Shine (2008) also showed that metamorph toads avoid areas containing such scent cues. Similar results were also reported by Cheivers et al. (1999). In this study, adult cane toads also seemed to avoid water containing the $\mathrm{H}_{2} \mathrm{O}$ extracted chemical cue, although there was no significant difference. The chemical cue extracted with $\mathrm{H}_{2} \mathrm{O}$ thus may appear to be repulsive to adult cane toads; thus, similar to post-metamorphic cane toads, it might be possible to control adult cane toads using this chemical cue. On Ishigaki Island, cane toads spawn primarily in rice fields, ponds, and artificial pools in sugarcane fields. Artificial pools in sugarcane fields appear to be the most important spawning sites, as numerous cane toads were found there (Haramura, personal observation). These artificial pools are small, and several of them are usually located at equal intervals. Therefore, if a strong chemical cue that adult cane toads ground for avoid, random spawning could be chemically prevented, and the toads could be led to specific artificial pools.

The specific behavioural responses elicited in cane toad tadpoles by chemical cues differ considerably among studies. For example, some authors reported that exposure to chemical cues from injured conspecifics renders toad tadpoles less active (Summey and Mathis 1998 for C. marinus), whereas others have report increased activity (Hews and Blaustein 1985 for Bufo boreas) or aggregation (Spieler and Linsenmair 1999 for B. maculatus). In any case, these results suggest that tadpoles react to chemical cues produced by other tadpoles. However, although cane toad tadpoles in Ishigaki exhibited increased swimming behaviour over time from this study, the tadpoles did not react significantly to either chemical cue $\left(\mathrm{H}_{2} \mathrm{O}\right.$ - or $\mathrm{MeOH}$-extracted sample). As indicated above, this may simply be due to the absence of chemical cues such as alarm pheromones in dead tadpoles or a little quantity of chemical substance using experiment could be also explained in this result.

The arena used in this study was small, and only swimming behaviour of tadpoles was recorded (the number of tadpoles swimming and the time individual tadpoles were engaged in swimming behaviour). Additional experiments assessing tadpole behaviour or phenotypic plasticity of cane toad tadpoles are needed. In Australia, cane toad tadpoles were shown to exhibit avoidance and dispersing behaviours following exposure to chemical cues produced by conspecifics (Hagman and Shine 2008). Moreover, repeated exposure to alarm pheromone was shown to reduce the survival rate of cane toad tadpoles and their body mass at metamorphosis (Hagman and Shine 
2009b, Clarke et al. 2016). Because more small metamorphs of cane toad are vulnerable to predators such as insects and to abiotic environmental factors such as desiccation (Child et al. 2008), chemical pheromones that induce small metamorphs would be powerful tools for controlling cane toad populations.

The idea that cane toad populations could be controlled using chemical cues remains speculative at present. However, chemical cues can have strong and specific effects limited only to the target species due to species-specific traits (Clarke et al. 2016). The alarm and attractant pheromones of cane toads have a powerful effect on the cane toad tadpoles but not on any of the native anuran species in Australia (Hagman and Shine 2008, 2009a, 2009b, Crossland et al. 2012). The result of this study was negative, and could not be conclusively isolated, however, negative results are also an important in the development of scientific thought (Weintraub 2016). Further detailed chemical studies involving living cane toad tadpoles is needed.

Acknowledgments: The author thanks Naoko Yoshinaga for extraction of the chemical pheromone from cane toad tadpoles and valuable comments on this study. He also thanks the students of Kyoto University (Yaken) for their help in the field experiments on Ishigaki Island. This research was supported by the Environment Research and Technology Development Fund (4RF-1402) of the Ministry of the Environment, Japan, and by an internal grant from The Hakubi Center, Kyoto University.

\section{LITERATURE CITED}

ALFORD, R. A., COHEN, M. P., CROSSlAnd, M. R., HEARNDEN, M. N. and SCHWARZKOPF, L. 1995. Population biology of Bufo marinus in northern Australia. In: Wetland Research in the WetDry Tropics of Australia. (Ed., Finlayson, C. M.) Office of the Supervising Scientist, Jabiru, pp. 173-181.

CHILD, T., PHILLIPS, B. L. and SHINE, R. 2008. The spatial ecology of cane toads (Bufo marinus) in tropical Ausltralia: Why do metamorph toads stay near the water? Austral Ecol. 33: 630-640.

CHIVERS, D. P., KIESECKER, J. M., WILDY, E. L., BELDEN, L. K., LEE, B. K. and BLAUSTEIN, A. R. 1999. Avoidance response of post-metamorphic anurans to cues of injured conspecifics and predators. J. Herpetol. 33: 472-476.

ClARKE, G. S., CROSSlAND, M. R. and SHINE, R. 2016. Can we control the invasive cane toad using chemicals that have evolved under intraspecific competition? Ecol. Appl. 26: 463-474.

CROSSlAND, M. R., HARAMURA, T., SALIM, A. A., CAPON, R. J. and SHINE, R. 2012. Exploiting intraspecific competitive mechanisms to control invasive cane toads (Rhinella marina). Proc. R. Soc. B. 279: 3436-3442.

FREELAND, W. J. and MARTIN, K. C. 1985. The rate of range expansion by Bufo marinus in northern Australia, 1980-84. Austral. Wildl. Res. 12: 555-559.

GOSNER, K. L. 1960. A simplified table for staging anuran embryos and larvae with notes on identification. Herpetologica 16: 183-190. 
HAGMAN, M. and SHINE, R. 2008. Understanding the toad code: Behavioural responses of cane toad (Chaunus marinus) larvae and metamorphs to chemical cues. Austral Ecol. 33: 37-44.

HAGMAN, M. and SHINE, R. 2009a. Species-specific communication systems in an introduced toad compared with native frogs in Australia. Aquatic Conserv. 19: 724-728.

HAGMAN, M. and SHINE, R. 2009b. Factors influencing responses to alarm pheromones by tadpoles of invasive cane toads (Bufo marinus). J. Chem. Ecol. 35: 265-271.

HEWS, D. K. and BLAUSTEIN, A. R. 1985. An investigation of the alarm response in Bufo boreas and Rana cascadae tadpoles. Behav. Neural Biol. 43: 47-57.

JMP, Version 9.0. SAS Institute Inc., Cary, NC.

KIDERA, N. and OTA, H. 2008. Can exotic toad toxins kill the native Ryukyu snakes? : Experimental and field observations on the effects of Bufo marinus toxins on Dinodon rufozonatum wall. Curr. Herp. 27: 23-27.

LEAVESLEY, A. J. and MAGRATH, R. D. 2005. Communicating about danger: Urgency alarm calling in a bird. Anim. Behav. 70: 365-373.

LEVER, C. 2001. The Cane Toad. The History and Ecology of a Successful Colonist. Westbury Scientific Publishing, Otley, West Yorkshire. 247 p.

MOGALI, S. M., SAIDAPUR, S. K., and SHANBHAG, B. A. 2013. Tadpoles of the bronze frog (Rana temporalis) assess predation risk before evoking antipredator defense behaviour. J. Ethol. 30: 379386.

OTA, H. 1999. Introduced amphibians and reptiles of the Ryukyu Archipelago, Japan. In: Problem snake management: The habu and the brown tree snake. (Eds., Rodda, G. H., Sawai, Y., Chiszar, D. and Tanaka, H.) Cornell University Press, New York. pp. 439-452.

PHILLIPS, B. L., BROWN, G. P. and SHINE, R. 2003. Assessing the potential impact of cane toads on Australian snakes. Conserv. Biol. 17: 1738-1747.

POLO-CAVIA, N., BURRACO, P. and GOMEZ-MESTRE, I. 2016. Low levels of chemical anthropogenic pollution may threaten amphibians by impairing predator recognition. Aquat. Toxicol. 172: 30-35.

PRAMUK, J. 2006. Phylogeny of South American Bufo (Anura: Bufonidae) inferred from combined evidence. Zool. J. Linn. Soc. 146: 407-452.

RAJCHARD, J. 2006. Antipredator pheromones in amphibians: A review. Vet. Med. 51: 409-413.

SHINE, R. 2010. The ecological impact of invasive cane toads (Bufo marinus) in Australia. Q. Rev. Biol. 85: 253-291.

SPIELER, M. and LINSENMAIR, K. E. 1999. Aggregation behaviour of Bufo maculatus as an antipredator mechanism. Ethology 105: 665-686.

SUMMEY, M. R. and MATHIS, A. 1998. Alarm responses to chemical stimuli from damaged conspecifics by larval anurans: Tests of three neotropical species. Herpetologica 54: 402-408.

TYLER, M. J. 1975. The cane Toad Bufo marinus: An Historical Account and Modern Assessment. Report on the Vermin and Noxious Weeds Destruction Board of Victoria and the Agriculture Protection Board of Western Australia, Melbourne (Australia). 52 p.

WASSERSUG, R. J. 1997. Assessing and controlling amphibian populations from the larval perspective. In: Amphibians in decline: Canadian studies of a global problem. (Ed., Green, M.) Herpetological conservation no. 1, Society for the Study of Amphibians and Reptiles, Saint Louis, MO, pp. 271-281.

WEINTRAUB, P. G. 2016. The importance of publishing negative results. J. Insect Sci. 16: 1-2. 